\title{
Determinação da Biodisponibilidade do Fósforo de Diferentes Fontes pela Técnica de Diluição Isotópica, em Suínos em Crescimento ${ }^{1}$
}

\author{
Alexandre de Oliveira Teixeira2 ${ }^{2}$, Darci Clementino Lopes $^{3}$, João Batista Lopes ${ }^{4}$, Dorinha Miriam Silber \\ S. Vitti ${ }^{5}$, Paulo Cezar Gomes ${ }^{3}$, Horacio Santiago Hostagno ${ }^{3}$, José Aparecido Moreira ${ }^{5}$, Félix Inácio ${ }^{6}$
}

RESUMO - Foram utilizados 28 leitões machos, com peso médio de 28,95 kg, para determinação das perdas endógenas fecais, da absorção verdadeira e da biodisponibilidade do fósforo de diferentes fontes. Utilizou-se o delineamento em blocos casualizados, com sete tratamentos e quatro repetições e um animal por unidade experimental. As rações foram à base de milho e de farelo de soja e o fósforo (P) foi suplementado com os fosfatos bicálcico (FBC), monobicálcico (MBC), superfosfato triplo (ST), superfosfato simples (SS), rocha catalão (ROCHA) e ácido fosfórico (AcF) e da ração-controle sem o P suplementar (CONT). Consumo, excreção por fezes e urina, retenção e absorção do fósforo foram inferiores na ração com menor nível de fósforo. O P inorgânico suplementar não influenciou o consumo, o P endógeno fecal e o P retido. Entretanto, a excreção de P nas fezes foi menor nos animais que consumiram SS e maior naqueles que consumiram ROCHA, enquanto a excreção de $\mathrm{P}$ na urina foi maior nos animais que consumiram AcF e menor naqueles que consumiram ROCHA. Concluiu-se que a disponibilidade biológica do P foi de 43,82; 89,44; 82,65; 76,90; 98,73; 90,03; e 63,26 para os tratamentos CONT, FBC, MBC, ST, SS, AcF e ROCHA, respectivamente.

Palavras-chave: absorção, metabolismo, nutrição, $\mathrm{P}^{32}$, radiofósforo, suínos

\section{Bioavailability Determination of Phosphorus from Different Sources, Using the Isotopic Dilution Technique, for Growing Swine}

\begin{abstract}
Twenty-eight male pigs averaging $28.95 \mathrm{~kg}$ were used to determine endogenous fecal losses, true absorption and phosphorus bioavailability in different phosphorus sources. The experiment was arranged in randomized blocks, with seven treatments and four repplicates and one pig/box. The diets were corn and soybean meal-based and the phosphorus (P) was supplemented through different phosphate sources: dicalcium (FBC), monodicalcium (MBC), triple superphosphate (ST), simple superphosphate (SS), Catalão rock (ROCHA) and phosphoric acid (AcF) and diet control without supplemental P (CONT). Phosphorus intake, excretion through feces and urine, retention and absorption were lower in the diet with smaller phosphorus level. Supplemental inorganic P did not affect intake, endogenous fecal P and retained P. However, the P excretion in the feces was smaller for the animals fed SS and greater for those fed ROCHA. P excretion in the urine was greater for the animals fed AcF and smaller for those fed ROCHA. It can be concluded P bioavailability was of 43.82, 89.44, 82.65, 76.90, 98.73, 90.03, and 63.26 for the treatments CONT, FBC, MBC, ST, SS, AcF and ROCHA, respectively.
\end{abstract}

Key Words: absorption, metabolism, nutrition, $\mathrm{P}^{32}$, radiophosphorus, swine

\section{Introdução}

O conhecimento da biodisponibilidade dos nutrientes dos ingredientes da ração é importante para balancear técnica e economicamente rações para suínos nas diferentes etapas do ciclo de produção.

A disponibilidade biológica do fósforo - medida pela resistência do elemento mineral a algum processo fisiológico (Peeler, 1972) - pode ser influenciada por fatores como nível e fonte de fósforo na ração, relação cálcio e fósforo, $\mathrm{pH}$ intestinal, antagonismo entre minerais, raças, linhagens e metodologia aplicada nos ensaios.

Entre as técnicas utilizadas para determinação da disponibilidade biológica do fósforo, estão a da relação dos coeficientes de regressão (Slope ratio) e os métodos da curva-padrão, da diluição isotópica e de Sullivan e a simulação do fluxo biológico.

\footnotetext{
1 Projeto parcialmente financiado pela BUNGE FERTILIZANTES S/A.

2 Zootecnista e doutor em Zootecnia - UFV - 36.571-000 - Viçosa - MG (alexandre.teixeira@bunge.com).

${ }^{3}$ Professor do Departamento de Zootecnia - UFV - 36.571-000 - Viçosa - MG.

4 Professor do Departamento de Zootecnia - UFPI - Teresina - PI.

${ }^{5}$ Pesquisadores do Departamento de Nutrição Animal - CENA/USP - Piracicaba - MG.

${ }^{6}$ Graduando em Zootecnia - UFV - 36.571-000 - Viçosa - MG.
} 
Os métodos das abscissas e o Slope ratio são comparativos e consideram apenas a absorção aparente do elemento, sem determinar suas perdas endógenas, e, por isso, subestima seu valor real (Bellaver et al., 1983). Por outro lado, a técnica de diluição isotópica, por meio de radiotraçadores, é a única que torna possível a determinação das perdas endógenas do elemento, o que permite ser considerada "real", enquanto as demais são "aparentes". Usando essa técnica, Fernandez (1995) verificou que a absorção de $\mathrm{P}$ foi regulada no intestino de maneira similar à do $\mathrm{Ca}$, ao passo que o balanço de fósforo foi regulado pela ação renal.

Em um estudo conduzido por Lopes (1998), com leitões no final da fase de crescimento consumindo $\mathrm{P}$ entre 62,6 e $121,1 \mathrm{mg} \mathrm{P} / \mathrm{kgPV} / \mathrm{dia}$, as perdas endógenas fecais não foram influenciadas pelos níveis de $\mathrm{P}$ consumido, indicando que os níveis ingeridos não foram suficientes para atender às exigências de $\mathrm{P}$ dos leitões. A disponibilidade biológica do fósforo do fosfato bicálcico, nesse ensaio, foi de $74,7 \%$, e a exigência para mantença dos leitões, baseando-se no nível zero de consumo de $\mathrm{P}$ na equação do $\mathrm{P}$ retido, foi de $28,81 \mathrm{mg} \mathrm{P} / \mathrm{kg} \mathrm{PV/dia.}$

Figueirêdo et al. (2001), estudando a disponibilidade biológica do fósforo dos fosfatos bicálcico, Tapira, Patos de Minas, monoamônico e superfosfato triplo, em suínos em crescimento, pela técnica de diluição isotópica, concluíram que a excreção de $\mathrm{P}$ fecal e urinária, o $\mathrm{P}$ endógeno fecal, a absorção e a retenção de $\mathrm{P}$ não foram afetados pelas diferentes fontes de $\mathrm{P}$. Constataram também que a biodisponibilidade do $\mathrm{P}$ das rações com fosfato bicálcico foi similar à daquelas com os fosfatos de rocha, cujo valor médio foi de $63 \%$. Em suínos em terminação, Figueirêdo et al. (1998) encontraram, para as mesmas fontes de fósforo, valor médio de $69 \%$ de biodisponibilidade, estando de acordo com os dados obtidos por Partridge (1981) e Bellaver et al. (1984), porém discordando de Bellaver et al. (1983).

Este estudo foi realizado com o objetivo de determinar a biodisponibilidade do fósforo, por meio da técnica de diluição isotópica, em diferentes fontes de fósforo, em suínos com $30 \mathrm{~kg}$ de peso.

\section{Material e Métodos}

O experimento foi conduzido no Setor de Suinocultura do Departamento de Zootecnia da Universidade Federal de Viçosa, em Viçosa, Minas
Gerais, no período de 19 de outubro a 5 de novembro de 2001.

Utilizaram-se 28 leitões machos, castrados, com peso médio de $28,95 \mathrm{~kg}$, distribuídos em delineamento de blocos casualizados, com sete tratamentos e quatro repetições. Foram utilizados como critério para formação dos blocos o peso e a idade dos animais.

Os animais foram alojados em gaiolas de estudos metabólicos, estruturadas para separar fezes e urina, com dispositivos para o fornecimento de alimento e de água semelhantes, às descritas por Pekas (1968). Após período de adaptação às gaiolas e às rações (sete dias), procedeu-se à coleta total de fezes e urina e de amostras diárias de sangue, durante os sete dias consecutivos. As amostras de fezes e urina e o plasma sangüíneo foram congelados a $-10^{\circ} \mathrm{C}$, para análises posteriores.

As rações foram à base de milho e de farelo de soja, sendo o P suplementado pelos fosfatos bicálcico (FBC), monobicálcico (MBC), superfosfato triplo (ST), superfosfato simples (SS), rocha catalão (ROCHA) e ácido fosfórico (AcF) e da ração-controle sem o P suplementar (CONT).

A composição das rações experimentais, com exceção do fósforo da ração-controle, foi formulada para atender às exigências nutricionais dos leitões, conforme recomendações de Rostagno et al. (2000). A composição centesimal e os valores nutricionais das rações experimentais são apresentados na Tabela 1.

$\mathrm{Na}$ fase de adaptação, as rações experimentais foram fornecidas à vontade, em duas refeições diárias (às $10 \mathrm{e} 18 \mathrm{~h}$ ), sendo o consumo devidamente registrado a cada repetição.

Durante a fase de coleta, as rações experimentais também foram distribuídas em duas refeições, porém com o consumo diário com base no peso metabólico $\left(\mathrm{W}^{0,75}\right)$, considerando-se o menor consumo dos animais de cada bloco, observado na fase préexperimental, quando receberam água à vontade.

No início da fase experimental, 7,4 MBq de ${ }^{32} \mathrm{P} /$ $0,05 \mathrm{~mL}$, na forma de fosfato de sódio $\left(\mathrm{Na}_{2} \mathrm{H}^{32} \mathrm{PO}_{4}\right)$, livre de carregador, foram injetados em cada animal, por via endovenosa.

A detecção da radioatividade nas amostras de fezes, urina e plasma foi realizada em espectrômetro de cintilação líquida por efeito Cerenkov (IAEA, 1979).

O conteúdo de fósforo inorgânico no plasma e na urina foi determinado por colorimetria, segundo Fiske \& Subbarrow (1925), e, nas rações e nas fezes, pelo método vanadato-molibdato (Sarruge \& Haag, 1974).

Os cálculos do percentual da atividade do ${ }^{32} \mathrm{P}$ 
Tabela 1 - Composição das rações experimentais

Table 1 - Composition of the experimental diets

\begin{tabular}{|c|c|c|c|c|c|c|c|}
\hline \multirow{2}{*}{$\begin{array}{l}\text { Ingredientes } \\
\text { Ingredients }\end{array}$} & \multicolumn{7}{|c|}{$\begin{array}{l}\text { Rações experimentais } \\
\text { Experimental diets }\end{array}$} \\
\hline & CONT & FBC & $\mathrm{MBC}$ & ST & SS & $\mathrm{AcF}$ & ROCHA \\
\hline Farelo de soja & 26,30 & 26,30 & 26,30 & 26,30 & 26,30 & 26,30 & 26,30 \\
\hline $\begin{array}{l}\text { Soybean meal } \\
\text { Milho }\end{array}$ & 68,00 & 68,00 & 68,00 & 68,00 & 68,00 & 68,00 & 68,00 \\
\hline $\begin{array}{l}\text { Corn } \\
\text { L-lisina } \\
\text { L-Lvsine } \mathrm{HCl}\end{array}$ & 0,10 & 0,10 & 0,10 & 0,10 & 0,10 & 0,10 & 0,10 \\
\hline $\begin{array}{l}\text { Sal } \\
\text { Salt }\end{array}$ & 0,30 & 0,30 & 0,30 & 0,30 & 0,30 & 0,30 & 0,30 \\
\hline $\begin{array}{l}\text { Calcário } \\
\text { Limestone }\end{array}$ & 1,72 & 0,99 & 1,17 & 1,28 & 0,36 & 1,78 & 0,00 \\
\hline $\begin{array}{l}\text { Fosfato bicálcico }{ }^{3} \\
\text { Dicalcium phosphate }\end{array}$ & - & 1,28 & - & - & - & - & - \\
\hline $\begin{array}{l}\text { Fosfato monobicálcico }{ }^{3} \\
\text { Monodicalcium phosphate }\end{array}$ & - & - & 1,18 & - & - & - & - \\
\hline $\begin{array}{l}\text { Superfosfato triplo } \\
\text { Triple superphosphate }\end{array}$ & - & - & - & 1,160 & - & - & - \\
\hline $\begin{array}{l}\text { Superfosfato simples } \\
\text { Simple superphosphate }\end{array}$ & - & - & - & - & 3,14 & - & - \\
\hline $\begin{array}{l}\text { Ácido fosfórico } \\
\text { Phosphoric acid }\end{array}$ & - & - & - & - & - & 1,02 & - \\
\hline $\begin{array}{l}\text { Fosfato rocha Catalão } \\
\text { Phosphate catalão rock }\end{array}$ & - & - & - & - & - & - & 1,88 \\
\hline Total & 100,00 & 100,00 & 100,00 & 100,00 & 100,00 & 100,00 & 100,00 \\
\hline $\begin{array}{l}\text { Composição calculada } 4 \\
\text { Calculated composition }{ }^{4}\end{array}$ & & & & & & & \\
\hline $\begin{array}{l}\text { Energia digestível ( } \mathrm{kcal} / \mathrm{kg}) \\
\text { Digestible energy }\end{array}$ & 3.400 & 3.400 & 3.400 & 3.400 & 3.400 & 3.400 & 3.400 \\
\hline $\begin{array}{l}\text { Proteína }(\%) \\
\text { Crude protein }\end{array}$ & 17,90 & 17,90 & 17,90 & 17,90 & 17,90 & 17,90 & 17,90 \\
\hline $\begin{array}{l}\text { Fósforo total }(\%) \\
\text { Total phosphorus }\end{array}$ & 0,321 & 0,560 & 0,560 & 0,560 & 0,560 & 0,560 & 0,560 \\
\hline $\begin{array}{l}\text { Cálcio }(\%) \\
\text { Calcium }\end{array}$ & 0,780 & 0,780 & 0,780 & 0,780 & 0,780 & 0,780 & 0,780 \\
\hline $\begin{array}{l}\text { Sódio }(\%) \\
\text { Sodium }\end{array}$ & 0,157 & 0,157 & 0,157 & 0,157 & 0,157 & 0,157 & 0,157 \\
\hline $\begin{array}{l}\text { Lisina total }(\%) \\
\text { Total lysine }\end{array}$ & 0,980 & 0,980 & 0,980 & 0,980 & 0,980 & 0,980 & 0,980 \\
\hline $\begin{array}{l}\text { Metionina }(\%) \\
\text { Methionine }\end{array}$ & 0,287 & 0,287 & 0,287 & 0,287 & 0,287 & 0,287 & 0,287 \\
\hline $\begin{array}{l}\text { Met. + cistina }(\%) \\
\text { Methionine+ cystine }\end{array}$ & 0,586 & 0,586 & 0,586 & 0,586 & 0,586 & 0,586 & 0,586 \\
\hline $\begin{array}{l}\text { Treonina }(\%) \\
\text { Threonine }\end{array}$ & 0,693 & 0,693 & 0,693 & 0,693 & 0,693 & 0,693 & 0,693 \\
\hline $\begin{array}{l}\text { Triptofano }(\%) \\
\text { Tryptophan }\end{array}$ & 0,212 & 0,212 & 0,212 & 0,212 & 0,212 & 0,212 & 0,212 \\
\hline 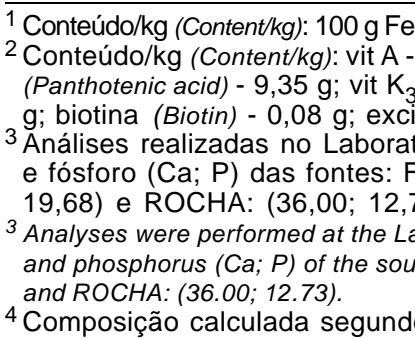 & $\begin{array}{l}\text { u; } 1 \mathrm{~g} \mathrm{Co} ; \\
000 \mathrm{Ul} ; \mathrm{D} \\
\text { g; ácido ni } \\
\text { (vehicle) } \\
\text { e Nutriçãc } \\
23,25 ; 18 \text {, } \\
\text { ry of Anim } \\
\text { C: (23.25; }\end{array}$ & $\begin{array}{l}\text { g Mn; } 100 \\
1.500 .00 \\
\text { tínico }(\mathrm{Ni} \\
\text { ip. - } 1.0 \\
\text { imimal do } \\
\text { ), MBC: } \\
\text { Jutrition o } \\
66), \text { MBC }\end{array}$ & $\begin{array}{l}\text { Zn; } 1,5 \mathrm{~g} \mathrm{l} ; \\
\mathrm{Jl} ; \mathrm{E}-15 . \mathrm{C} \\
\text { inic acid) - } \\
\text { g. } \\
\text { epartame } \\
, 5 ; 20,29 \\
\text { Departme } \\
\text { 9.5;20.29 }\end{array}$ & $\begin{array}{l}0 \mathrm{~g} \text { excip } \\
\mathrm{Ul} ; \mathrm{B} \\
0 \mathrm{~g} \text {; vit } \\
\text { de Zoot } \\
\mathrm{T}:(16,4 \\
\\
\text { f Animal } \\
\text { T: }(16.46\end{array}$ & $\begin{array}{l}\text { (vehicle) } \\
\mathrm{B}_{2}-4 \mathrm{~g} \\
20,0 \mathrm{~g} ; \\
\mathrm{da} \text { UF } \\
, 63), \mathrm{S} \\
\text { nce of U } \\
\text { 3), SS: ( }\end{array}$ & 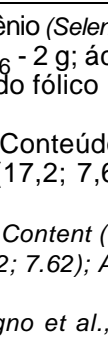 & $\begin{array}{l}\text { - } 0,3 \text { g q.s.p. } \\
\text { pantotênico } \\
\text { lic acid) - } 0,6 \\
\text { \%) de cálcio } \\
\text { AcF: }(0,00 ; \\
\text { of the calcium } \\
\text { (0.00; } 19.68)\end{array}$ \\
\hline
\end{tabular}

R. Bras. Zootec., v.33, n.5, p.1231-1237, 2004 
injetado no plasma e nas fezes e das atividades específicas (AE) no plasma e nas fezes foram feitos de acordo com Lofgreen (1960). O valor do fósforo endógeno fecal, por sua vez, foi determinado com base em Comar et al. (1953) e Vitti (1989):

- Atividade injetada $\left(\mathrm{AI}{ }^{32} \mathrm{P}\right)=[$ (contagem por minuto de $1 \mathrm{~mL}$ de plasma ou $1 \mathrm{~g}$ de fezes/ contagem por minuto de uma solução-padrão) $\mathrm{x}$ 100];

- $\mathrm{AE}={ }^{32} \mathrm{P} / \mathrm{P}$ total;

- $\% \mathrm{P}$ endógeno fezes $=($ atividade específica do ${ }^{32} \mathrm{P}$ das fezes/atividade específica do ${ }^{32} \mathrm{P}$ do plasma) x 100; e

- $\mathrm{P}$ endógeno total das fezes $=\%$ do $\mathrm{P}$ endógeno nas fezes x P total excretado nas fezes.

As taxas de absorção real do fósforo foram determinadas pela relação entre a absorção real e o $\mathrm{P}$ consumido; a biodisponibilidade do fósforo das fontes foi encontrada por meio de fracionamento do $\mathrm{P}$ consumido e o absorvido real entre a raçãocontrole e as rações contendo as fontes fosfatadas (Figueirêdo, 2001).

A análise estatística dos parâmetros estudados nos experimentos foi realizada de acordo com o programa Statistical Analysis System (SAS, 1996). Para comparação das médias, utilizou-se o teste Student-Newman-Keuls.

\section{Resultados e Discussão}

Os resultados referentes ao ensaio de metabolismo do fósforo, em função das rações experimentais, são apresentados na Tabela 2.

Houve diferença $(\mathrm{P}<0,05)$ entre o $\mathrm{P}$ consumido, $\mathrm{P}$ excretado nas fezes, $\mathrm{P}$ excretado na urina, $\mathrm{P}$ absorvido, $\mathrm{P}$ retido e biodisponibilidade de $\mathrm{P}$ nas rações entre as fontes.

$\mathrm{O}$ consumo de $\mathrm{P}$ foi menor $(\mathrm{P}<0,05)$ nos animais que consumiram a ração CONT que nos demais tratamentos. Pesquisas têm demonstrado que a ingestão de $\mathrm{P}$ está associada ao seu nível dietético na ração (Fernandez, 1995; Lopes, 1998; Figueirêdo et al., 2001). Neste estudo, o consumo de fósforo foi, em média, de 6,78 e $3,40 \mathrm{~g} /$ dia para os tratamentos que receberam fonte suplementar de $\mathrm{P}$ e para o tratamento CONT, respectivamente. Bellaver et al. (1983) e Bellaver et al. (1984) observaram consumo, em rações-controle semelhantes, de 3,10 e 3,97 g de P/dia para leitões de 21,16 e $29,53 \mathrm{~kg}$ de peso, respectivamente.

\footnotetext{
R. Bras. Zootec., v.33, n.5, p.1231-1237, 2004
}

O teor de $\mathrm{P}$ total excretado nas fezes foi influenciado $(\mathrm{P}<0,05)$ pelas fontes de fósforo, pois os animais que consumiram a ração sem o $P$ suplementar (CONT) e os que consumiram a ração contendo superfosfato simples (SS) excretaram menos $\mathrm{P}$, enquanto aqueles que consumiram rações contendo rocha catalão (ROCHA) excretaram maior quantidade de $\mathrm{P}$ nas fezes.

O fósforo excretado pela urina foi influenciado $(\mathrm{P}<0,05)$ pelas fontes suplementares de fósforo. Animais que consumiram CONT, FBC e MBC excretaram menos $\mathrm{P}$, aumentando a excreção quando foram incluídos na ração ST, SS e AcF. Resultados semelhantes foram obtidos por Vipperman Jr. et al. (1974), Fernandez (1995), Lopes et al. (1999b) e Figueirêdo et al. (2001), em pesquisa com suínos, ao observarem que o teor de fósforo nas fezes e na urina elevou-se com o aumento do nível dietético de fósforo.

A maior excreção de $\mathrm{P}$ na urina pelos animais que consumiram ração contendo ácido fosfórico sugere que a absorção de fósforo dietético excedeu as necessidades metabólicas dos animais, diminuindo proporcionalmente a retenção de P. Nesse sentido, Georgievskii (1982) e Breves \& Schröder (1991) relataram que a excreção de fósforo pela urina funciona como importante mecanismo de controle homeostático do fósforo em monogástricos.

Segundo Borges (1991), a regulação da excreção/ reabsorção de $\mathrm{P}$ renal é influenciada pelos níveis de $\mathrm{P}$ plasmáticos e pelo balanço ácido-básico da dieta.

O balanço dietético ácido-básico, também denominado equilíbrio cátion-aniônico (ECA), referese ao balanço entre as cargas positivas (cátions) e negativas (ânions) dos íons presentes nos alimentos que, ao serem absorvidos no trato digestivo, influenciam o equilíbrio ácido-básico nos fluidos corporais, alterando o metabolismo e, conseqüentemente, o desempenho dos animais. O ECA pode ser calculado em miliequivalentes (meq) por kg de MS da ração (Patience, 1990).

Os valores de $\mathrm{P}$ endógeno fecal foram semelhantes $(\mathrm{P}>0,05)$ entre os tratamentos, o que também foi verificado por Broce (1986) e Figueirêdo et al. (2001). Cupák et al. (1972) e Jongbloed et al. (1992) relataram que o $\mathrm{P}$ endógeno fecal para suínos varia de 5 a $10 \mathrm{mg}$ $\mathrm{P} / \mathrm{kg}$ p.v/dia, valores próximos aos 4,65 mg P/kg p.v/dia de perdas endógenas, encontrados por Bellaver et al. (1983). Por outro lado, Fernandez (1995) e Lopes et al.(1999b) observaramincremento nas perdas endógenas, em função do aumento do nível de fósforo da ração. 


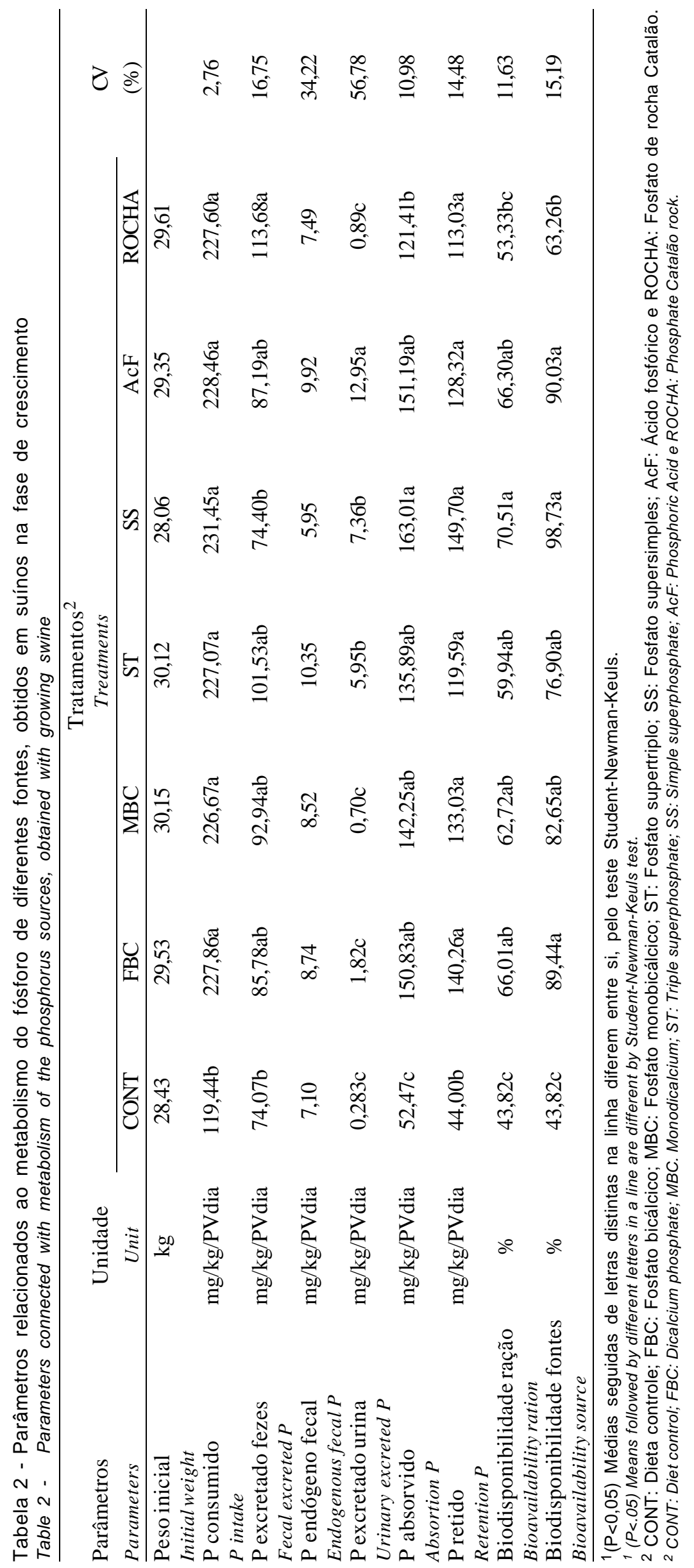

R. Bras. Zootec., v.33, n.5, p.1231-1237, 2004 
Os animais que consumiram a ração CONT, seguidos daqueles que consumiram ração contendo ROCHA, apresentaram menor nível de $\mathrm{P}$ absorvido. Os valores de absorção para FBC, MBC, ST e AcF foram intermediários $(\mathrm{P}>0,05)$ e semelhantes entre si, observando-se o maior valor quando se utilizou o superfosfato simples. O P retido foi menor $(\mathrm{P}<0,05)$ nos animais que consumiram a ração-controle (CONT) e semelhante nos demais tratamentos.

Observou-se menor eficiência na retenção $(83,85 \%)$ do fósforo absorvido de dietas à base de milho e de farelo de soja (CONT), em relação à eficiência média de $90,67 \%$ nas dietas contendo fonte suplementar de P. Segundo Guéguen et al. (1968), Vitti (1989) e Figueirêdo et al. (2001), essa diferença pode estar associada, no sangue, à discriminação metabólica do elemento, em razão de sua origem, ou ao aumento da relação Ca:P promovido pela inclusão de calcário na dieta CONT. Resultados semelhantes foram obtidos por Bellaver et al. (1984), Lopes et al. (1999a,b) e Figueirêdo et al. (2001), ao passo que Cupák et al. (1972) e Bellaver et al. (1983) não constataram diferença no balanço de fósforo entre as dietas com e sem $\mathrm{P}$ suplementar.

A ração-controle (CONT), em que todo fósforo era de origem vegetal, apresentou menor biodisponibilidade de fósforo $(43,82 \%)$ em relação aos demais tratamentos, em razão da predominância do fósforo fítico. Figueirêdo et al. (2001), em suínos com peso médio de $45,95 \mathrm{~kg}$, encontraram biodisponibilidade de $\mathrm{P}$ superior (49\%) em rações à base de milho e de farelo de soja. O valor encontrado neste trabalho está de acordo com os da literatura, em que a biodisponibilidade de fósforo de rações à base de cereais varia entre 18 e $60 \%$, com média de $33 \%$, para suínos de 23 a $41 \mathrm{~kg}$ (Guéguen et al., 1968; Nolland et al., 1968; Peeler, 1972).

A taxa de absorção do fósforo das rações contendo as fontes fosfatadas foi, em média, de $63,13 \%$. Vipperman Jr. et al. (1974), Bellaver et al. (1983), Partridge (1981), Bellaver et al. (1984), Lopes et al. (1999a,b) e Figueirêdo et al. (2001), trabalhando com dietas e metodologias semelhantes, obtiveram taxas de absorção real de P de 45,86; 51,0; 59,61; 59,49; 56,$9 ;$ e $57,14 \%$, respectivamente, inferiores, portanto, às deste trabalho.

A biodisponibilidade de $\mathrm{P}$ suplementar variou de 63,26 a 98,73, diferindo $(\mathrm{P}<0,05)$ entre as fontes estudadas. Estes resultados foram superiores aos de Bellaver et al. (1984), Partridge (1981) e Faria (1995).
A biodisponibilidade de $\mathrm{P}$ do fosfato bicálcico, quando se eliminou a interferência do $\mathrm{P}$ de origem vegetal, foi de $89,44 \%$, sendo semelhante ao de $90,34 \%$, encontrado por Lopes et al. (1999b); superior aos de 75,3 e 71,9\%, verificados, respectivamente, por Cupak et al. (1983) e Figueirêdo et al. (2001); e inferior ao de $101,93 \%$, obtido por Bellaver et al. (1983). Com relação ao ST, observou-se que a biodisponibilidade do P foi de 76,9\%, superior aos $66,3 \%$ registrados por Figueirêdo et al. (2001). Para o fosfato de rocha, a média de $63,26 \%$ de biodisponibilidade foi inferior à de $73,05 \%$, verificada por Figueirêdo et al. (2001).

\section{Conclusões}

A disponibilidade biológica do fósforo foi de 43,82 ; 89,$44 ; 82,65 ; 76,90 ; 98,73 ; 90,03$; e $63,26 \%$ para os tratamentos controle, fosfato bicálcico, fosfato monobicálcico, superfosfato triplo, superfosfato simples, ácido fosfórico e rocha catalão, respectivamente.

\section{Literatura Citada}

BELLAVER, C., GOMES, P.C., SANTOS, D.L. Absorção e disponibilidade de fósforo para suínos, baseada na diluição de radiofósforo (32 P). Pesquisa Agropecuária Brasileira, v.18, n.9, p.1053-1057, 1983.

BELLAVER, C.; GOMES, P.C.; FIALHO, E.T. et al. Absorção e disponibilidade do fósforo de fosfatos naturais em rações para suínos. Pesquisa Agropecuária Brasileira, v.19, n.12, p.1513-1518, 1984.

BORGES, F.M.O. Utilização do fósforo disponível de dez fontes de fósforo para frangos de corte. Belo Horizonte: Universidade Federal de Minas Gerais, 1991. 56p. Dissertação (Mestrado em Zootecnia) - Universidade Federal de Minas Gerais, 1991.

BREVES, G.; SCHRÖDER, B. Comparative aspects of gastrointestinal phosphorus metabolism. Nutrition Research Reviews, v.4, p.125-140, 1991.

BROCE, C.S. Comparação entre diferentes fontes de fósforo em rações para suínos nas fases de crescimento e terminação. Santa Maria: Universidade Federal de Santa Maria, 1986. 67p. Dissertação (Mestrado em Zootecnia) Universidade Federal de Santa Maria, 1986.

COMAR, C.L.; MONROE, R.A.; VISEK, W.J. et al. Comparison of two isotope methods for determination of endogenous fecal calcium. Journal of Nutrition, v.50, p.459-67, 1953.

CUPÁK, M.; PROCHAZKA, Z.; JAMBOR, V. Utilization of phosphorus compounds in pigs after endogenous phosphorus determination means of ${ }^{32} \mathrm{P}$. Acta Veterinaria Brno, v.41, p.257-262, 1972.

FARIA, S.R. Determinação da biodisponibilidade de fósforo e a avaliação de desempenho de suínos em cinco fontes fosfatadas. Belo Horizonte: Universidade Federal de Minas Gerais, 1995. 86p. Dissertação (Mestrado 
em Nutrição de Monogástricos) - Universidade Federal de Minas Gerais, 1995.

FERNANDEZ, J.A. Calcium and phosphorus metabolism in growing pigs. II. Simultaneous radio-calcium and radiophosphorus kinetics. Livestock Production Science, v.41, n.1, p.243-254, 1995.

FIGUEIRÊDO, A.V.; VITTI, D.M.S.S.; LOPES, J.B. et al. Disponibilidade biológica do fósforo de fontes fosfatadas determinada por intermédio da técnica de diluição isotópica. II. Suínos em crescimento. Revista Brasileira de Zootecnia, v.30, n.5, p.1514-1520, 2001.

FIGUEIRÊDO, A.V.; VITTI, D.M.S.S.; LOPES, J.B. Disponibilidade biológica do fósforo de cinco fosfatos, determinada com suínos em terminação, através do uso de radiotraçador. In: REUNIÃO ANUAL DA SOCIEDADE BRASILEIRA DE ZOOTECNIA, 35., 1998, Botucatu. Anais... Botucatu: Sociedade Brasileira de Zootecnia, 1998. p.204-206.

FISKE, C.H.; SUBBARROW, Y. The calorimetric determination of phosphorus. Journal Biological Chemistry, v.66, n.2, p.375-400, 1925.

GEORGIEVSKII, V.I. The phisiological role of macroelements. In: GEORGIEVSKII, V.I.; ANNENKOV, B.N.; SAMOKHIN, V.I. (Eds.) Mineral nutrition of animals. 1.ed. London: Butterworths, 1982. p.91-170.

GUÉGUEN, L.; BESANÇON, P.; RERAT, A. Utilization digestive, cinétique de l'absorption et afficacité de la rétention du phosphore phytique chez le porc. Annales de Biologie Animale Biochimie Biophysique, v.8, p.273-280, 1968.

INTERNATIONAL ATOMIC ENERGY AGENCY - IAEA. Laboratory training manual on the use of nuclear techniques in animal research. Vienna: IAEA, 1979, 299p. (Technical Report Series, 193).

JONGBLOED, A.W.; MROZ, Z.; KEMME, P.A. The effect of suplementary Aspergilus niger phytasein diets for pigss on concentration and apparent digestibility of dry sections of the alimentary tract. Journal of Animal Science, v.70, n.4, p.1159-1168, 1992.

LOFGREEN, G.P. The availability of the phosphorus in dicalcium phosphate, bone meal, soft phosphate and calcium phytates for mature weathers. Journal Nutrition, v.70, n.1, p.58-62, 1960.

LOPES, J.B. Avaliação da absorção real e das perdas endógenas de fósforo para suínos pela técnica de diluição isotópica. Piracicaba: Universidade de São Paulo, 1998. 87p. Tese (Doutorado em Ciência Animal) - Centro de Energia Nuclear na Agricultura, Universidade de São Paulo, 1998.

LOPES, J.B.; VITTI, D.M.S.S.; FIGUEIRÊDO, A.V. et al. Absorção real, perdas endógenas e exigências de fósforo para suínos em final de crescimento pela técnica da diluição isotópica. Arquivo Brasileiro Medicina Veterinária Zootecnia, v.51, n.4, p.353-358, 1999a.
LOPES, J.B.; VITTI, D.M.S.S.; FIGUEIRÊDO, A.V. et al. Avaliação das perdas endógenas e das exigências de fósforo, por meio da técnica da diluição isotópica, para suínos em crescimento. Revista Brasileira de Zootecnia, v.28, n.4, p.773-778, 1999b.

NOLAND, P.R.; FUNDERBURG, M.; JOHNSON, Z. Phosphorus availability in pratical diet for swine. Journal of Animal Science, v.27, n.4, p.115, 1968.

PARTRIDGE, I.G. A comparison of defluorinated rock phosphate and dicalcium phosphate, in diets contining either skim milk powder or soybean meal as the main protein supplement for early weaned pigs. Animal Prodution, v.3, n.1, p. 67-73, 1981.

PATIENCE, J.F. A review of the role of acid-base balance in amino acid nutrition. Journal of Animal Science, v.68, n.2, p. 398-408, 1990.

PEELER, H.T. Biological availability of nutrients in feeds: availability of major mineral ions. Journal of Animal Science, v.35, n.3, p.695-712, 1972.

PEKAS, J.C. Versatile swine laboratory apparatus for physiologic and metabolic studies. Journal of Animal Science, v.27, n.5, p.1303-1306, 1968.

ROSTAGNO, H.S.; ALBINO, L.F.T.; DONZELE, J.L. et al. Tabelas brasileiras para aves e suínos: composição de alimentos e exigências nutricionais. Viçosa, MG: Universidade Federal de Viçosa, 2000. p.141.

SARRUGE, J.R.; HAAG, H.P. Análises químicas em plantas. Piracicaba: Escola Superior de Agricultura Luis de Queiroz, 1974. 56p.

STATISTICAL ANALYSES SYSTEM - SAS. SAS System for Windows. release 6.12 Cary: 1996 (01 CD-ROM).

VIPPERMAN JR., P.E.; PEO JR., E.R.; CUNNINGHAM, P.J. Effect of dietary calcium and phosphorus level upon calium, phosphorus and nitrogen balance in swine. Journal of Animal Science, v.38, n.4, p.758-765, 1974.

VITTI, D.M.S.S. Avaliação da disponibilidade biológica do fósforo dos fosfatos bicálcico, Patos de Minas, Tapira e finos de Tapira para ovinos pela técnica de diluição isotópica. Piracicaba: Universidade de São Paulo, 1989. 87p. Tese (Doutorado Ciência Animal) - Centro de Energia Nuclear na Agricultura, Universidade de São Paulo, 1989. 